EGU2020-22102

EGU General Assembly 2020

(c) Author(s) 2020. This work is distributed under

the Creative Commons Attribution 4.0 License.

\title{
Developing new approaches and strategies for teaching Physical Geography and Geomorphology: the role of AIGeo (Italian Association of Physical Geography and Geomorphology)
}

\author{
Irene Maria Bollati ${ }^{1,2}$ \\ ${ }^{1}$ Università degli Studi di Milano, Earth Science Department A. Desio, 20133, Italy (irene.bollati@unimi.it) \\ ${ }^{2}$ AIGeo (Italian Association of Physical Geography and Geomorphology)
}

The researches carried out by the AIGeo (Italian Association of Physical Geography and Geomorphology) members, also in collaboration with other researchers, cover various important topics of the Environmental and Earth Sciences. Geomorphology is central, also in the framework of dissemination strategies that are implemented and elaborated. A particular focus is, in fact, addressed to the development of educational strategies and applications focusing on landscape evolution through space and time having as target both students and teachers. The proposed strategies include fieldworks, multimedia activities and multidisciplinary approaches addressed mainly to secondary schools. In the Italian framework, the Ministerial National Guidelines provide indications about teaching these topics in the secondary schools. The guidelines indicate specifically, for the secondary schools of 2 nd level, the topics and novelties concerning Physical Geography and Geomorphology. Among the general goals referred to the secondary school of 1st level, the landscape observation and the related natural phenomena are approached by the Geography teachers and by the Science teachers. Herein, we present an overview on the AIGeo activities regarding education in Physical Geography and Geomorphology. Some examples of the most recent researches planned and tested for the secondary school (1st and 2nd level) will be outlined. Moreover, the initiatives addressed specifically to present and future teachers will be illustrated too. 